\title{
$\mathfrak{J} \mathfrak{n} \mathfrak{b} \mathfrak{a} \mathfrak{l} \mathbf{t}$
}

\section{Bermifite Bebidte.}

Briej an setrn bon Bore, als or allb Franfrria nad atalient reiste. In Jabr 1764. . . . . . . . . . . . 9

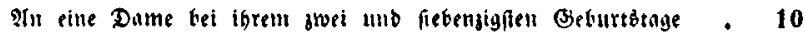

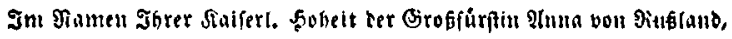
Ia fie allf einem Ball jum Beburtỏtag ifgrer Durdjlatedtigfien Frau Mutter als Titunia erid)len . . . . . . . . 13

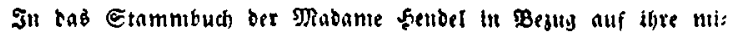
mifchen Rorfellungen ou Botga ben 17. Januar 1810 . .

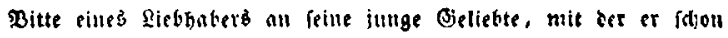
pinige sect beriprodhen mar ............ . 17

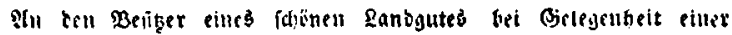
verungliatten Befarribumg davon . . . . . . . . . 18

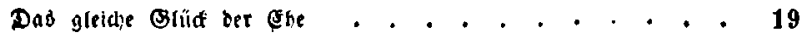

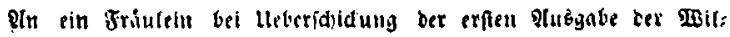
belntine 1764 . . . . . . . . . . . . . 20

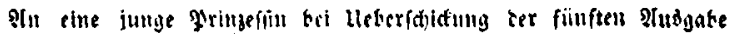
ter geifhelmine . + . . . . . . . . . . . . 22 
Erive

Prolog im Namen eines jungen Yringen bel ber Borfellung eines Deutiden Gaduipiels nu Dem Giburtotage feitter Frau Calvepter 26

Dns Gilü ber Sirbe . . . . . . . . . . . . . 28

Der Bweiffer . . . . . . . . . . . . . . . . 29

Der sjeldentod . . . . . . . . . . . . . . . 89

Ila eine Deutfae Didgterin . . . . . . . . . . . . 30

Der Befild . . . . . . . . . . . . . . . 31

Iuf cinch Mefruten bur Pieldbarme . . . . . . . . 31

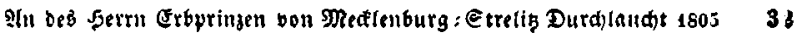

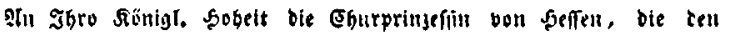

Plutor, als er ebetl in Bertin war, bu feinem Beburtäbase,

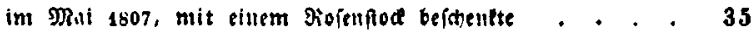

Der Bogelfetler . . . . . . . . . . . . . . 36

Des Jäger abenbtied . . . . . . . . . . . . 37

Monnanse int Danten unb Jum Bortbeil einco reifenden siluers,

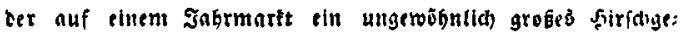

weibe für Ejeld reben lies. . . . . . . . . . . 99

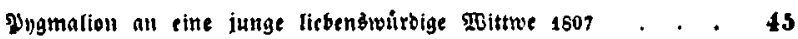

Das entflogente sanar. Pln Ebendiefelbe . . . . . . . . 55

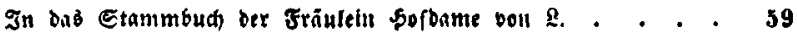

Eefpräa . . . . . . . . . . . . . . . . . 61

Der sefer bes foral . . . . . . . . . . . . 62

Eefpría) . . . . . . . . . . . . . . . 69

q11 eitien 9 (rjt in feill Stammbud) . . . . . . . . . 64

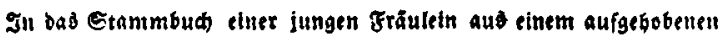

Silofier . . . . . . . . . . . . . . 65

In bas Etammbuah eines relienten Ruffen . . . . . . 66

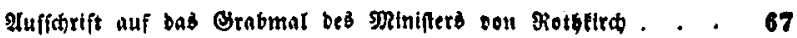

श्fuf befien Frau Gemablin . . . . . . . . . . . 67

Ill has Stammbuh bon Dordph Meife . . . . . . , 68 


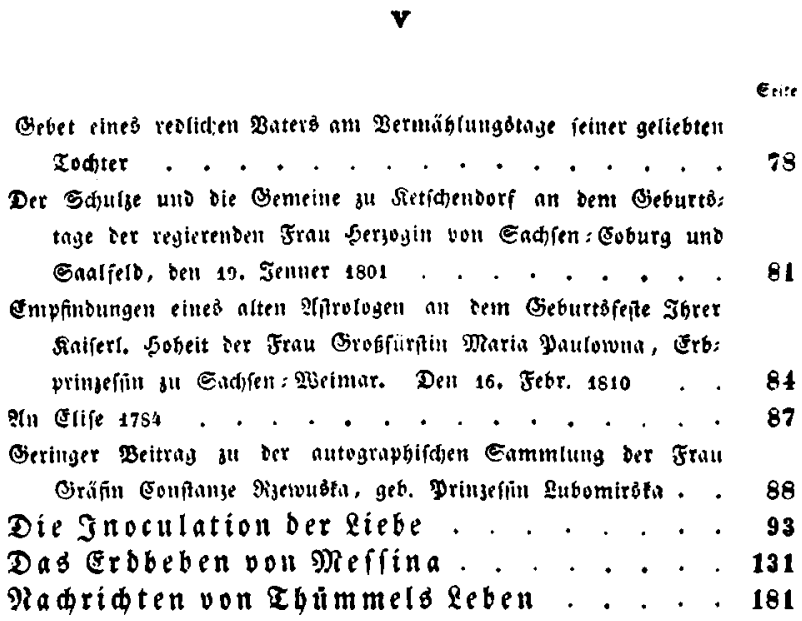


